\title{
Is Physical Therapy the Early Solution for Post-Acute Myocardial Infarction Patients? A Meta-Analysis
} \author{
Theodora Benedek ${ }^{1,4}$ \\ 1 University of Medicine, Pharmacy, Sciences and Technology Târgu Mureș, Romania \\ 2 Clinic of Rheumatology, County Clinical Emergency Hospital, Târgu Mureș, Romania \\ 3 TopMed Medical Center, Târgu Mureș, Romania \\ ${ }^{4}$ Clinic of Cardiology, County Clinical Emergency Hospital, Târgu Mureș, Romania
}

Monica Copotoiu1,2, Mihaela-Maria Șușcă¹, Horațiu Popoviciu11,2, Daniela Popescu³,

\section{CORRESPONDENCE}

Mihaela-Maria Șușcă

Str. Gheorghe Marinescu nr. 38

540139 Târgu Mureș, Romania

Tel: +40 265215551

E-mail:mela_doc@yahoo.com

\section{ARTICLE HISTORY}

Received: October 30, 2020

Accepted: November 30, 2020
Monica Copotoiu • Str. Gheorghe Marinescu nr. 38 , 540139 Târgu Mureș, Romania. Tel: +40 265215551 E-mail: monicacopotoiu@gmail.com

Horațiu Popoviciu • Str. Gheorghe Marinescu nr. 38 540139 Târgu Mureș, Romania. Tel: +40 265215 551, E-mail: phoratiu2000@gmail.com

Daniela Popescu • Str. Dorobanților nr. 1-11, 540156 Târgu Mureș, Romania. Tel: +40 365424 575, E-mail: danapopescu90@gmail.com

Theodora Benedek • Str. Gheorghe Marinescu nr. 38 540139 Târgu Mureș, Romania. Tel: +40 265215 551, E-mail: theodora.benedek@gmail.com

\begin{abstract}
Background: Physical rehabilitation is essential to improve the quality of life of patients with acute myocardial infarction (AMI). Study aim: The study intended to demonstrate the benefits of early rehabilitation in patients with AMI. Material and method: We performed a meta-analysis to document the benefits of physical treatment in patients who suffered an AMI. Studies were searched in the following databases: PubMed, PlosOne, Mendeley, and clinicaltrials.gov. The terms used in our research were "rehabilitation", "physical exercise", "physical training" "quality of life", "early", and "post Ml". The inclusion criteria consisted in the assessment of the following parameters: heart rate, maximal/submaximal capacity, and characteristics of the left ventricle end-diastolic volume, ejection fraction, and left ventricle hypertrophy included in the study design. Results: The database search identified 710 studies, of which only 10 passed the inclusion criteria. Out of 1,515 patients who underwent early physical therapy, 960 reported improvement in the quality of their life $(p<0.001)$. A number of 2,703 patients out of a total of 3,595 underwent a complete physical treatment and medication program. From the ten studies included in the meta-analysis, six had a positive feedback to the multimodal treatment within 1 month post-AMI. Patients who performed physical exercises within a month after the cardiac arrest (1,103 post-AMI patients from a total of 1,278 ) demonstrated a high heterogeneity represented by the coefficient $12=84 \%$ but with a significant statistical value of $p<0.00001$. Conclusion: Early physical therapy initiation significantly improves the quality of life of patients with AMI.
\end{abstract}

Keywords: physical therapy, myocardial infarction, early exercise

\section{INTRODUCTION}

The quality of life of patients suffering from an acute myocardial infarction (AMI) depends of several variables. The main consequence of AMI is left ventricular remodeling, and several studies have shown its improvement in patients who benefited from physical treatment following an acute myocardial infarction. 


\section{PURPOSE}

The purpose of this study was to demonstrate the benefits of early rehabilitation in patients with AMI.

\section{MATERIAL AND METHODS}

We performed a meta-analysis to document the benefits of physical treatment in patients who suffered an AMI. The terms used in our research were "rehabilitation", "physical exercise", "physical training" "quality of life", "early", and "post MI". The inclusion criteria consisted in the assessment of the following parameters: heart rate, maximal/submaximal capacity, and characteristics of the left ventricle - end-diastolic volume, ejection fraction, and left ventricle hypertrophy in the design of the study. ${ }^{1-4}$ Statistical analysis was performed using RevMan 5.4 software.

\section{RESULTS}

The database search identified 710 studies, of which only 10 passed the inclusion criteria, including a number of 1,061 patients out of a total of 1,546 who participated in a complete physical treatment and medication program.

The first question was whether the life of patients with myocardial infarction had improved after early initiation of kinesiotherapy. A number of 2,475 patients out of 3,526 who underwent early physical therapy reported improvement in the quality of their life (Figure 1). Improvement in the quality of life has been defined as improvement of

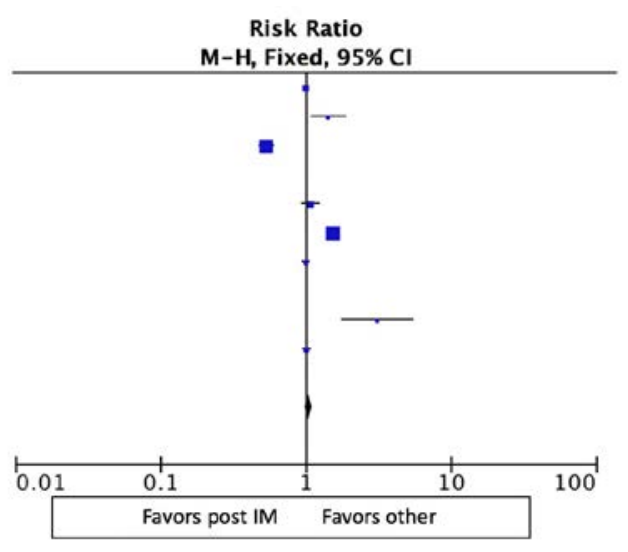

FIGURE 1. Forest plot diagram of the studies with patients whose quality of life has improved after post-MI rehabilitation

the following conditions: fatigue, depression, daily activities. The answers to the first question are summarized in Table 1.

The Cochrane-Q number $(\mathrm{df}=7)$ was 265.68 , with $\mathrm{I}^{2} \mathrm{ex}-$ pressing a $97 \%$ heterogeneity $(\mathrm{p}<0.07, \mathrm{Z}=1.79)$. $\mathrm{I}^{2}$ represents study heterogeneity as studies with different designs that can induce biased data. All patients who underwent a complete physical training exhibited an improvement in their quality of life, demonstrating that early initiation of physical exercise has a positive impact on quality of life in the post-infarction period.

The next hypothesis we have intended to verify was related to the effectiveness of the physical rehabilitation program after one month in patients that had presented with myocardial infarction.

TABLE 1. Effect of initiation of rehabilitation measures post AMI

\begin{tabular}{|c|c|c|c|c|c|c|}
\hline \multirow[t]{2}{*}{ Study or Subgroup } & \multicolumn{2}{|c|}{ Experimental } & \multicolumn{2}{|l|}{ Control } & \multirow[t]{2}{*}{ Weight } & \multirow[t]{2}{*}{ Odds Ratio } \\
\hline & Events & Total & Events & Total & & \\
\hline Soleimani et al. ${ }^{5}$ (2008) & 178 & 178 & 62 & 62 & $10.0 \%$ & $1.00[0.98,1.02]$ \\
\hline Kim et al. ${ }^{6}$ (2014) & 18 & 18 & 18 & 26 & $1.7 \%$ & $1.42[1.09,1.85]$ \\
\hline Hansen et al.7 (2008) & 170 & 334 & 330 & 343 & $35.2 \%$ & $0.53[0.48,0.59]$ \\
\hline Giallauria et al. ${ }^{8}$ (2006) & 15 & 15 & 0 & 0 & & Not estimable \\
\hline Chen et al. ${ }^{9}$ (2015) & 50 & 64 & 561 & 770 & $9.3 \%$ & $1.07[0.94,1.23]$ \\
\hline Larsen et al..$^{10}$ (2011) & 382 & 528 & 430 & 908 & $34.2 \%$ & $1.53[1.40,1.67]$ \\
\hline Kargarfard et al. ${ }^{11}$ (2010) & 35 & 35 & 37 & 37 & $3.9 \%$ & $1.00[0.95,1.05]$ \\
\hline Andjic et al.12 (2016) & 60 & 60 & 0 & 0 & & Not estimable \\
\hline Izeli et al. ${ }^{13}$ (2016) & 18 & 18 & 8 & 26 & $0.8 \%$ & $3.09[1.76,5.42]$ \\
\hline Sumide et al. ${ }^{14}$ (2009) & 34 & 34 & 69 & 70 & $5.0 \%$ & $1.01[0.96,1.06]$ \\
\hline Total (95\% Cl) & 1,284 & & 2,272 & & $100 \%$ & $1.04[1.00,1.10]$ \\
\hline Total events & 960 & & 1,515 & & & \\
\hline
\end{tabular}


TABLE 2. Effectiveness of the rehabilitation program within one month post AMI

\begin{tabular}{|c|c|c|c|c|c|c|}
\hline \multirow[t]{2}{*}{ Study or Subgroup } & \multicolumn{2}{|c|}{ Experimental } & \multicolumn{2}{|l|}{ Control } & \multirow[t]{2}{*}{ Weight } & \multirow[t]{2}{*}{ Odds Ratio } \\
\hline & Events & Total & Events & Total & & \\
\hline Soleimani et al. ${ }^{5}$ (2008) & 178 & 178 & 62 & 62 & & Not estimable \\
\hline Kim et al. ${ }^{6}$ (2014) & 18 & 18 & 18 & 26 & $0.2 \%$ & $17.00[0.91,316.49]$ \\
\hline Hansen et al.7 (2008) & 272 & 334 & 339 & 343 & $31.4 \%$ & $0.05[0.02,0.14]$ \\
\hline Giallauria et al. ${ }^{8}$ (2006) & 15 & 15 & 13 & 15 & $0.2 \%$ & $5.74[0.25,130.37]$ \\
\hline Chen et al. ${ }^{9}$ (2015) & 50 & 64 & 561 & 834 & $8.8 \%$ & $1.74[0.94,3.20]$ \\
\hline Larsen et al.10 (2011) & 382 & 528 & 380 & 430 & $58.6 \%$ & $0.34[0.24,0.49]$ \\
\hline Kargarfard et al.11 (2010) & 35 & 35 & 37 & 37 & & Not estimable \\
\hline Andjic et al. ${ }^{12}$ (2016) & 60 & 60 & 60 & 60 & & Not estimable \\
\hline Izeli et al. ${ }^{13}$ (2016) & 18 & 18 & 8 & 26 & $0.1 \%$ & $80.53[4.33,1499.20]$ \\
\hline Sumide et al..$^{14}$ (2009) & 33 & 34 & 69 & 70 & $0.7 \%$ & $0.48[0.03,7.89]$ \\
\hline Total $(95 \% \mathrm{Cl})$ & 1,284 & & 1,903 & & $100 \%$ & $0.50[0.39,0.63]$ \\
\hline Total events & 1,061 & & 1,547 & & & \\
\hline
\end{tabular}

Heterogeneity: $\mathrm{Chi}^{2}=58.73, \mathrm{df}=6(\mathrm{p}<0.00001) ; \mathrm{I}^{2}=90 \%$

Test for overall effect: $Z=5.75(p<0.00001)$

From the 10 studies analyzed, 7 studies had a positive feedback regarding the multimodal treatment within one month post myocardial infarction (Table 2).

This analysis presented a high heterogeneity $\left(\mathrm{I}^{2}=90 \%\right.$, $\mathrm{p}<0.00001)$. In this regard, the most appropriate study design was the one published by Chen et al. in 2015 (Figure 2). This study included 60 patients with AMI, of which 50 participated in a physical exercise program within one month after the cardiac event. ${ }^{9}$ The studies that had crossed the "no effect" line were not statistically significant for our meta-analysis (Figure 2).

The next hypothesis was whether kinesiotherapy has been beneficial for post-AMI patients. Out of the 10 studies, six had statistical significance for our meta-analysis, with a $\mathrm{p}$ value $<0.00001$ (Table 3 , Figure 3 ).

In a study by Chen et al. (2015), beneficial changes have been noticed after kinesiotherapy in 610 out of 834 patients. ${ }^{9}$

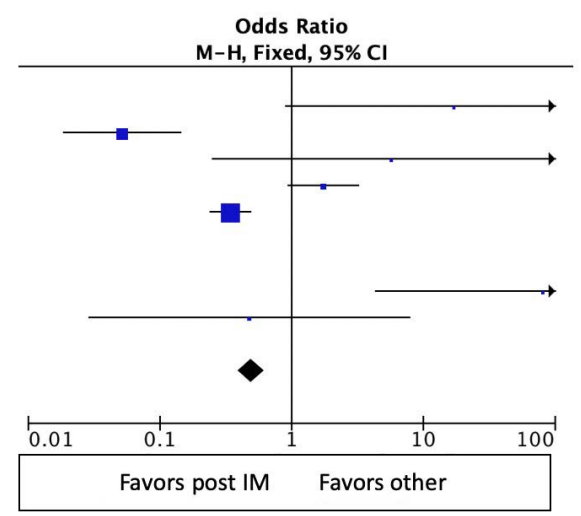

FIGURE 2. Forest plot diagram of the studies with patients who underwent a rehabilitation program within one month post MI
Even though the heterogeneity of the studies was low compared with the outcomes of other studies, only the studies of Chen et al. ${ }^{9}$ and Izeli et al. ${ }^{13}$ did not cross the "no effect" line, therefore being statistically significant for our meta-analysis. However, the study of Izeli et al. had to be dismissed due to its inappropriate design and limitations (Figure 3).13

The question whether the implementation of an exercise program within one week at most after the cardiac event would be beneficial for post-AMI patients could not be elucidated because there were no relevant data identified in the medical literature.

The last hypothesis addresed in this meta-analysis was related to the rehabilitation program, whether this should be initiated early or within one month after the cardiac event. The following data were obtained: the limits of the confidence interval between 2.04 and 3.09

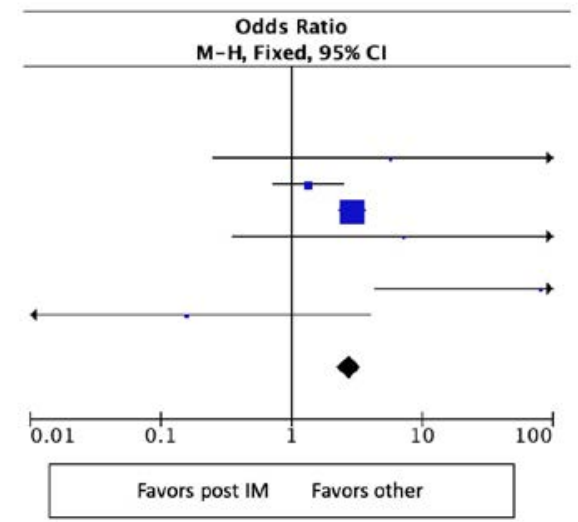

FIGURE 3. Forest plot diagram of the studies with patients who benefited from kinesiotherapy post MI 
TABLE 3. Effect of kinesiotherapy post AMI

\begin{tabular}{|c|c|c|c|c|c|c|}
\hline \multirow[t]{2}{*}{ Study or Subgroup } & \multicolumn{2}{|c|}{ Experimental } & \multicolumn{2}{|l|}{ Control } & \multirow[t]{2}{*}{ Weight } & \multirow[t]{2}{*}{ Odds Ratio } \\
\hline & Events & Total & Events & Total & & \\
\hline Soleimani et al. ${ }^{5}$ (2008) & 62 & 62 & 178 & 178 & & Not estimable \\
\hline Kim et al. ${ }^{6}(2014)$ & 18 & 18 & 26 & 26 & & Not estimable \\
\hline Hansen et al. ${ }^{7}$ (2008) & 334 & 334 & 343 & 343 & & Not estimable \\
\hline Giallauria et al. ${ }^{8}$ (2006) & 15 & 15 & 13 & 15 & $0.5 \%$ & $5.74[0.25,130.37]$ \\
\hline Chen et al. ${ }^{9}$ (2015) & 50 & 64 & 56 & 770 & $2.0 \%$ & $45.54[23.72,87.41]$ \\
\hline Larsen et al.10 (2011) & 382 & 548 & 430 & 908 & $94.6 \%$ & $2.91[2.31,3.66]$ \\
\hline Kargarfard et al. ${ }^{11}(2010)$ & 35 & 25 & 34 & 37 & $0.5 \%$ & $7.20[0.36,144.67]$ \\
\hline Andjic et al..$^{12}(2016)$ & 60 & 60 & 60 & 60 & & Not estimable \\
\hline Izeli et al..13 (2016) & 18 & 18 & 8 & 26 & $0.2 \%$ & $80.53[4.33,1499.20]$ \\
\hline Sumide et al. ${ }^{14}$ (2009) & 33 & 34 & 70 & 70 & $2.2 \%$ & $0.16[0.01,3.99]$ \\
\hline Total $(95 \% \mathrm{Cl})$ & 1,168 & & 2,433 & & $100 \%$ & $3.91[3.17,4.81]$ \\
\hline Total events & 1,007 & & 1,218 & & & \\
\hline
\end{tabular}

Heterogeneity: $\mathrm{Chi}^{2}=68.88, \mathrm{df}=5(\mathrm{p}<0.00001) ; \mathrm{I}^{2}=93 \%$

Test for overall effect: $Z=12.80(p<0.00001)$

with a $\mathrm{Z}$ value of 8.73 , and a statistical significance of $\mathrm{p}$ $<0.00001$, favoring the early initiation of the rehabilitation program in post-AMI patients. Nevertheless, study heterogeneity was still high, with $\mathrm{I}^{2}=84 \%$. According to the forest diagram, the study with the narrowest confidence interval was the one conducted by Kim et al. in 2014, which still crossed the "no effect" line. ${ }^{6}$ This study included 18 patients, of which 8 responded better to the early initiation of the kinesiotherapy program (Figure 4).

Five out of 10 studies did not have sufficient weight to be considered relevant in this analysis. The only study that did not cross the „no effect” line was the one conducted by
Chen et al. in 2015, in which that the majority of patients (50 out of 64) benefited from early rehabilitation. ${ }^{9}$

\section{DISCUSSIONS}

The present study on the quality of life of post-AMI patients who underwent physical rehabilitation has identified that physical therapy might be the early solution for post-AMI subjects.

The study aimed to address five questions regarding post-AMI patients: 1) whether their quality life has improved after early initiation of kinesiotherapy; 2) wheth-

TABLE 4. Effect of early kinesiotherapy post MI

\begin{tabular}{|c|c|c|c|c|c|c|}
\hline \multirow[t]{2}{*}{ Study or Subgroup } & \multicolumn{2}{|c|}{ Experimental } & \multicolumn{2}{|l|}{ Control } & \multirow[t]{2}{*}{ Weight } & \multirow[t]{2}{*}{ Odds Ratio } \\
\hline & Events & Total & Events & Total & & \\
\hline Soleimani et al. ${ }^{5}$ (2008) & 172 & 172 & 62 & 62 & & Not estimable \\
\hline Kim et al. ${ }^{6}$ (2014) & 8 & 18 & 18 & 26 & $6.9 \%$ & $0.36[0.10,1.24]$ \\
\hline Hansen et al.7 (2008) & 334 & 334 & 343 & 343 & & Not estimable \\
\hline Giallauria et al.8 (2006) & 15 & 15 & 15 & 15 & & Not estimable \\
\hline Chen et al. ${ }^{9}$ (2015) & 50 & 64 & 560 & 770 & $15.8 \%$ & $1.34[0.73,2.47]$ \\
\hline Larsen et al..$^{10}$ (2011) & 382 & 528 & 430 & 908 & $73.3 \%$ & $2.91[2.31,3.66]$ \\
\hline Kargarfard et al..$^{11}$ (2010) & 30 & 35 & 34 & 37 & $4.0 \%$ & $0.53[0.12,2.40]$ \\
\hline Andjic et al. ${ }^{12}$ (2016) & 60 & 60 & 60 & 60 & & Not estimable \\
\hline Izeli et al. ${ }^{13}$ (2016) & 18 & 18 & 8 & 26 & $0.2 \%$ & $80.53[4.33,1499.20]$ \\
\hline Sumide et al. ${ }^{14}$ (2009) & 34 & 34 & 70 & 70 & & Not estimable \\
\hline Total (95\% Cl) & 1,278 & & 2,317 & & $100 \%$ & $2.51[2.04,3.09]$ \\
\hline Total events & 1,103 & & 1,600 & & & \\
\hline
\end{tabular}




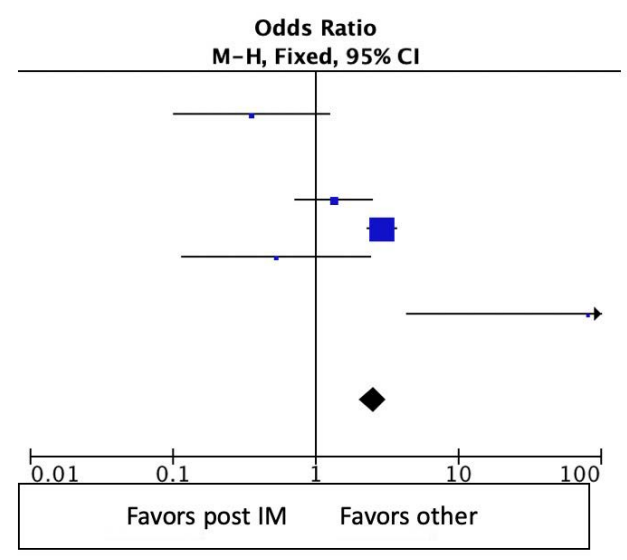

FIGURE 4. Forest plot diagram of the studies with patients who benefited from early kinesiotherapy post MI

er the physical rehabilitation program is efficient at one month post AMI; 3) whether kinesiotherapy has beneficial effects; 4) whether the implementation of an exercise program within one week at most after the cardiac event would be beneficial; and 5) whether the rehabilitation program should be started early or within a month from the acute cardiac event.

Our results have shown that early initiation of physical therapy may improve the quality of life of patients with AMI. Similarly to our results, a report by Haykowsky et al. published in 2015 found that kinesiotherapy is beneficial in the post-AMI phase, and a kinesiotherapy program initiated early could improve the rehabilitation of these patients. ${ }^{15} \mathrm{~A}$ meta-analysis published by Taylor et al. in 2004, which included 48 trials on a total of 8,940 patients, confirmed the benefits of cardiac rehabilitation for patients with coronary heart disease. ${ }^{16}$ Also, in 2019, Ji et al. published a meta-analysis which demonstrated that cardiac rehabilitation reduces the recurrence of myocardial infarction. ${ }^{17}$

\section{CONCLUSIONS}

In conclusion, early initiation of physical therapy may improve the quality of life of patients with AMI and may reduce ventricular remodeling. Kinesiotherapy within one month from the index event may have a significant beneficial role in patients with cardiovascular diseases, especially following an AMI. An early initiated kinesiotherapy program could improve the rehabilitation of post-AMI patients. However, there is limited data on the benefits of ur- gent initiation of a physical rehabilitation program, within one week after the event, therefore this hypothesis should be further analyzed in larger scale studies.

\section{CONFLICT OF INTEREST}

Nothing to declare.

\section{REFERENCES}

1. Egger M, Davey Smith G, Schneider M, Minder C. Bias in meta-analysis detected by a simple, graphical test. BMJ. 1997;315:629-634.

2. Higgins JPT, Thompson SG, Deeks JJ, Altman DG. Measuring inconsistency in meta-analyses. BMJ. 2003;327:557-560

3. Petrie A, Bulman JS, Osborn JF. Further statistics in dentistry Part 8 : Systematic reviews and meta-analyses. Br Dent J. 2003;194:73-78.

4. Sterne JA, Egger M. Funnel plots for detecting bias in meta-analysis: guidelines on choice of axis. J Clin Epidemiol. 2001;54:1046-1055.

5. Soleimani A, Alidoosti M, Salarifar M, Kassaian SE, Karimi A, Davoodi S, et al. Effect of Cardiac Rehabilitation Program on Heart Rate Recovery after Percutaneous Coronary Intervention and Coronary Artery Bypass Grafting. J Tehran Univ Heart Cent. 2008:3:11-16.

6. Kim C, Jung H, Choi HE, Kang SH. Cardiac Rehabilitation After Acute Myocardial Infarction Resuscitated From Cardiac Arrest. Ann Rehabil Med. 2014:38:799-804

7. Hansen D, Dendale P, Berger J, Onkelinx S, Reyckers I, Hermans A, et al. Importance of exercise training session duration in the rehabilitation of coronary artery disease patients. Eur J Cardiovasc Prev Rehabil Off J Eur Soc Cardiol Work Groups Epidemiol Prev Card Rehabil Exerc Physiol. 2008:15:453-459.

8. Giallauria F, De Lorenzo A, Pilerci F, Manakos A, Lucci R, Psaroudaki M, et al. Long-term effects of cardiac rehabilitation on end-exercise heart rate recovery after myocardial infarction. Eur J Cardiovasc Prev Rehabil Off J Eur Soc Cardiol Work Groups Epidemiol Prev Card Rehabil Exerc Physiol. 2006;13:544-550

9. Chen H-M, Liu C-K, Chen H-W, Shia B-C, Chen M, Chung C-H. Efficiency of rehabilitation after acute myocardial infarction. Kaohsiung J Med Sci. 2015;31:351-357.

10. Larsen KK, Vestergaard M, Søndergaard J, Christensen B. Rehabilitation status three months after first-time myocardial infarction. Scand J Prim Health Care. 2011:29:210-215.

11. Kargarfard M, Rouzbehani R, Basati F. Effects of Exercise Rehabilitation on Blood Pressure of Patients after Myocardial Infarction. Int J Prev Med. 2010;:1:124-130.

12. Andjic M, Spiroski D, llic Stojanovic O, Vidakovic T, Lazovic M, Babic D, et al. Effect of short-term exercise training in patients following acute myocardial infarction treated with primary percutaneous coronary intervention. Eur J Phys Rehabil Med. 2016;52:364-369.

13. Izeli NL, dos Santos AJ, Crescêncio JC, Gonçalves ACCR, Papa V, Marques F, et al. Aerobic Training after Myocardial Infarction: Remodeling Evaluated by Cardiac Magnetic Resonance. Arq Bras Cardiol. 2016:106:311-318.

14. Sumide T, Shimada K, Ohmura H, Onishi T, Kawakami K, Masaki Y, et al. Relationship between exercise tolerance and muscle strength following cardiac rehabilitation: comparison of patients after cardiac surgery and patients with myocardial infarction. J Cardiol. 2009;54:273-281.

15. Haykowsky M, Scott J, Esch B, Schopflocher D, Myers J, Paterson I, et al. A meta-analysis of the effects of exercise training on left ventricular remodeling following myocardial infarction: start early and go longer for greatest exercise benefits on remodeling. Trials. 2011;12:92.

16. Taylor RS, Brown A, Ebrahim S, Jolliffe J, Noorani H, Rees K, et al. Exercisebased rehabilitation for patients with coronary heart disease: systematic review and meta-analysis of randomized controlled trials. Am J Med. 2004;116:682-692.

17. Ji H, Fang L, Yuan L, Zhang Q. Effects of Exercise-Based Cardiac Rehabilitation in Patients with Acute Coronary Syndrome: A Meta-Analysis Med Sci Monit Int Med J Exp Clin Res. 2019;25:5015-5027. 